\title{
Determination of Rational Design and Geometric Parameters of a High-Performance Drill Based on a Mathematical Model of the Cutting Part
}

\author{
Petr Pivkin ${ }^{1,2,3,4}$, Vladimir Grechishnikov ${ }^{2}$, Artem Ershov $^{1,2,3,4}$ Vladimir Kuptsov $^{3}$ and Xiaohui Jiang $^{5}$ \\ ${ }^{1}$ Dept. of High-Efficiency Processing Technologies, Moscow State University of Technology “STANKIN”, RU-127055, Moscow, \\ Russia \\ ${ }^{2}$ Dept. of Cutting Tools and Shaping Technologies, Moscow State University of Technology “STANKIN”, RU-127055, Moscow, Russia \\ ${ }^{3}$ Lab. of Micromachining Technologies, Moscow State University of Technology “STANKIN”, RU-127055, Moscow; Russia \\ ${ }^{4}$ Center of Cognitive Technologies and Machine Vision, Moscow State University of Technology “STANKIN”, RU-127055, Moscow; \\ Russia \\ ${ }^{5}$ Department of Mechanical Design, Manufacturing and Automation, University of Shanghai for Science and Technology, CH-200093 \\ Shanghai, China
}

\begin{abstract}
Processing of high-precision holes in one technological operation is an urgent problem of advanced manufacturing. Processing of precise holes in parts for aerospace and machine-building industries with a diameter of up to $30 \mathrm{~mm}$ is performed during countersinking, deployment or grinding operations. These operations are applied only if there already exists a pre-treated hole. Monolithic three-fluted drills have been becoming common for processing high-precision holes of 7-8 quality over the last few years. The processing of various types of materials such as stainless steels, cast iron and heat-resistant steels requires rational geometric and structural parameters of the cutting tool. The nature of the load distribution between all the teeth during drilling plays a huge role in the processing efficiency. Even load distribution between the three teeth and a positive geometry improves self-centering and reduces the deviation from the specified axis of the hole. The drill sharpening provides positive geometry along the entire main cutting edge. The influence of the geometric parameters of the cutting edge of the screw groove on the shape of the drill bit is equally important. Existing approaches to the design of the thinning do not account for the influence of the geometric parameters of the cutting edge on the section of the screw groove. Analytical approaches to modelling of the main cutting edges are typically married with difficulties associated with achieving a smooth change in the angle of inclination to the tangent of the cutting edge. The complexity of the aforementioned task is largely due to the presence of critical points at the interface of the spiral groove and thinning. Determining the rational shape of two sections of the main cutting edge performed in this study is a complicated task that includes several steps needed to find the number of nodal points. Achieving a positive rake angle in the normal section to the cutting edge at the gash area that was formed via a special sharpening is one of the most important results of this paper. The rational shape of the cutting edge and the front surface provides an increase in the strength of the cutting part by 1.3 times.
\end{abstract}

\section{Introduction}

Three-fluted designs of monolithic drills have better selfcentering due to the convergence of three cutting edges at one point at the top and a more uniform load distribution due to three cutting teeth [1], which together increases the productivity of hole processing with high precision requirements. Since the advent of threepronged designs, various designs have been developed that can improve accuracy, durability or processing performance. The working surfaces of such structures have a complex profile geometry. They provide a more rational distribution of geometric parameters. Thus, the back surface of the cutting part of the drill as a screw is sharpening, allows not only smoother distribution of the values of the back angle along the main cutting edge, but also lower values on the transverse front cutting edge due to the stabilization of the cutting process. With the radial shape of the cutting part [1-2] reducing stress concentrations at the edge corners, the shape of the back surface is formed along a curve lying on a spherical surface, thereby forming a complex profile surface. The curvature on the undercut also forms the front surface of a complex shape.

The complexity of designing such drills lies in the formation of these surfaces with taking into account the interaction of the totality of all shapes and geometric parameters. Thus, the design of the gash depends on the shape and location of the edge on the screw groove section, which in turn depends on the shape and 
geometric parameters of the chip groove and the back surface.

Existing approaches to the design of such types of drills do not functionally link the shape of the cutting part and the groove profile, in order to achieve the desirable shape of the main cutting edge that affects the stability of the cutting process. The straight shape of the cutting edge is optimal for the best cutting stability due to a uniform distribution of geometric parameters along the edge. An equally important design element is sharpening of the main cutting edge to reduce the length of the section with a negative front angle, which prevents the cutting process during drilling. Existing approaches to the design of the gash do not take into account the shape of the edge. There are various types and shapes of gash, with the most common being straight and radius gashes. Straight-line sharpening is performed at a certain angle from the main cutting edge to the top of the drill, forming a sharp transition at the junction of the two sections. The radius sharpening is also performed at some angle to the vertex, but in a radius shape. In this case, a sharp transition can be avoided at the expense of the optimal curvature of the undercut. In the first case, the sharp transition forms a zone of stress concentrations, which under load during cutting can lead to breakage of the drill. In the second case, the uneven distribution of the angle of inclination along the entire section of the cutting edge contributes to an uneven load, which leads to a loss of productivity. The optimal shape of the undercut should take into account the shape of the main cutting edge on the chip groove section [3-47].

\section{Results and Discussion}

As discussed earlier, the section of the main cutting edge determines the starting point and shape of the gash. It is worth noting that with a different shape of the main cutting edge, the curvature and position of the gash will also change. The formation of a straight cutting edge shape requires the construction of a mathematical model of the surfaces forming the cutting edge. Such surfaces are the screw surface of the chip groove and the conical surface. It is their intersection that forms the main cutting edge in the undercut area. The profile of the chip groove in the radial section is determined by the formula (1).

The slope of the cutting edge in the chip groove section is determined by the angle " 1 " of the blade relative to the line on the conical surface connecting the beginning of the cutting edge at the corner and the tip of the drill.

$$
\begin{aligned}
& X k(X)= \\
& X \cdot \cos \left[\frac{2 \pi \cdot\left[R-\sqrt{\left(R+X \cdot \tan \left(\frac{\pi}{2}-\iota\right)\right)^{2}-X^{2}}\right]}{T \cdot \tan (\varphi)}\right]+
\end{aligned}
$$

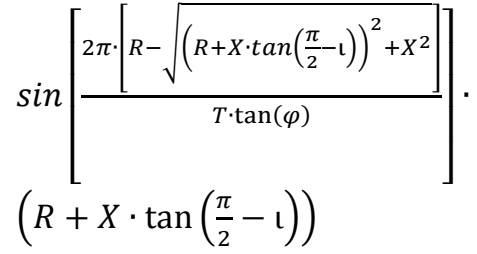

$Y k(X)=\cos \left[\frac{2 \pi \cdot\left[R-\sqrt{\left(R+X \cdot \tan \left(\frac{\pi}{2}-\iota\right)\right)^{2}-X^{2}}\right]}{T \cdot \tan (\varphi)}\right]$.

$\left(R+X \cdot \tan \left(\frac{\pi}{2}-\iota\right)\right)-X \cdot$

$\sin \left[\frac{2 \pi \cdot\left[R-\sqrt{\left(R+X \cdot \tan \left(\frac{\pi}{2}-\iota\right)\right)^{2}+X^{2}}\right]}{T \cdot \tan (\varphi)}\right]+$

$\sin \left[\frac{2 \pi \cdot\left[R-\sqrt{\left(R+X \cdot \tan \left(\frac{\pi}{2}-\iota\right)\right)^{2}+X^{2}}\right]}{T \cdot \tan (\varphi)}\right]$.

$\left(R+X * \tan \left(\frac{\pi}{2}-\iota\right)\right)$

The profile of the chip groove consists of two circles tangent to each other, as well as tangent to the inner diameter of the drill. The circle rk1 also touches the front surface located at an angle $\gamma \mathrm{k}$.

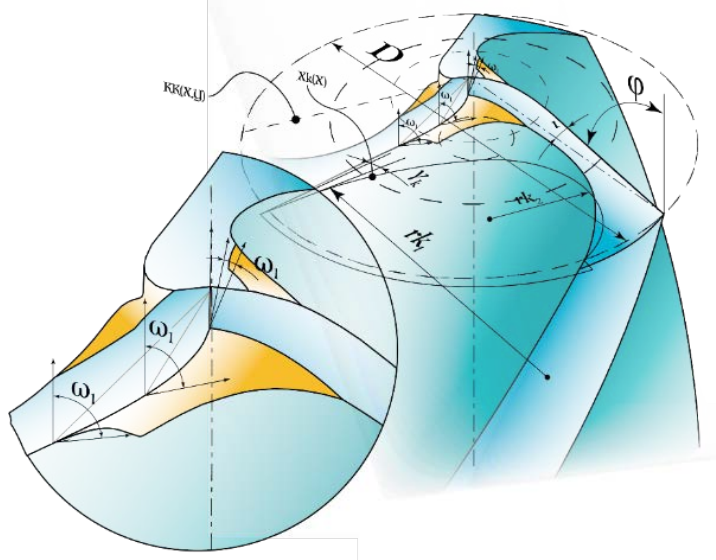

Fig. 1. Chart of the three-fluted drill design

The profile of the chip groove consists of two circles tangent to each other, as well as tangent to the inner diameter of the drill. The circle rk1 also touches the front surface located at an angle $\gamma \mathrm{k}$.

The next step, after modeling the main working surfaces, based on a mathematical model, is to build a section of the gash. In the polar coordinate system, on a plane perpendicular to the tool axis, a spline tangent to the cutting edge is defined with a different number of reference points. The resulting spline is projected onto a conical surface. The description of the conical surface is determined by the formula (3): 


$$
\begin{aligned}
& K K(X, Y) \\
& =\left[\begin{array}{c}
X \cdot \cos (\varphi)-\frac{\sin (\varphi) \cdot\left(R-\sqrt{X^{2}+Y^{2}}\right)}{\tan (\varphi)} \\
\left.\sin (\theta) \cdot\left[X \cdot \sin (\varphi)+\frac{\cos (\varphi) \cdot\left(R-\sqrt{X^{2}+Y^{2}}\right)}{\tan (\varphi)}\right]\right) \\
+Y(\phi, \theta) \cdot \cos (\theta)
\end{array}\right]
\end{aligned}
$$

The spatial curve on the surface is the cutting edge on the gash area.

Thus, changing the number of nodal points of the sharpening edge from 3 to 10 , we get 7 different designs of the cutting part of the drill. It should be noted that on a design with 4 reference points, the shape of the cutting edge is slightly distorted. An edge with 3 nodal points loses its original shape, acquiring a more rectilinear curvature. Changing the shape of the cutting edge introduces a limitation in the formation of optimal curvature, which entails a narrower range of processed materials. The structures with the 9th, 7th and 5th reference points are shown in Figure 2.

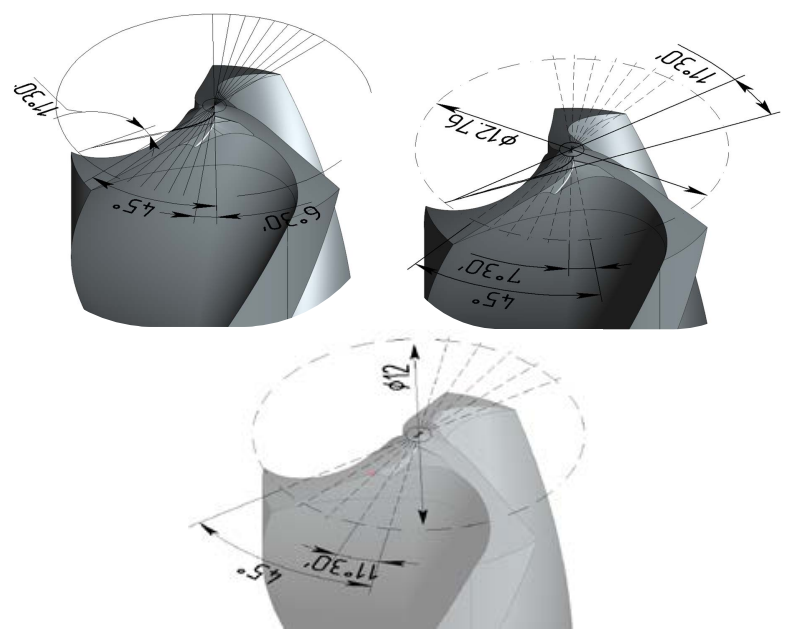

Fig. 2. Areas of the gash with the 9th, 7th and 5th reference points

The next step is to study the curvature of the gash section, by measuring the angle of inclination of the cutting edge $\omega 1$ (Fig. 1), along the entire section on each structure. - the angle between the tangent to the cutting edge and the axis of the drill in a plane perpendicular to the line passing through the test point and the tip of the drill.

Measurements of each structure were carried out at 11 equidistant points. The graph will allow you to determine the design with the most uniform distribution of the angle of inclination of the cutting edge.

The graph shows that the smoothest distribution of the angle on structures with 3 and 4 reference points, as a result of a more rectilinear shape of the edge. These structures, as mentioned above, have distortions of the edge shape, so they cannot be selected as optimal. The design with 5 reference points is devoid of this disadvantage, as a result of which it is defined as an optimal design.

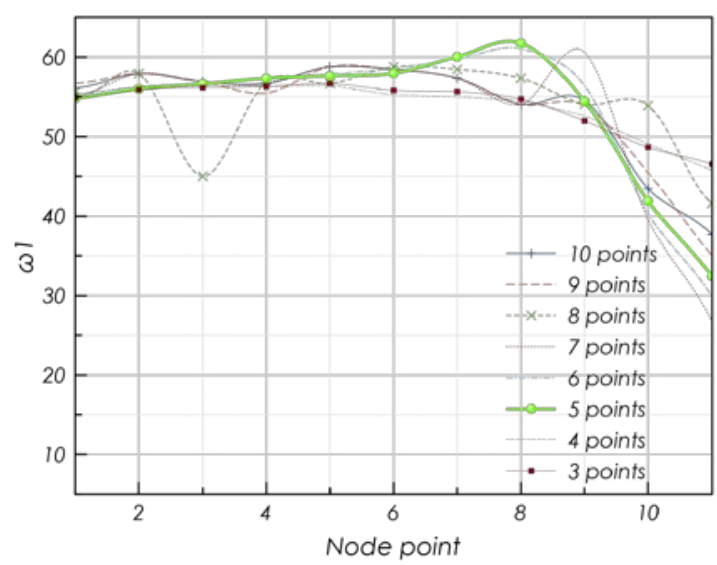

Fig. 4. Graph of the change of the angle $\omega 1$ along the cutting edge in the section of the gash

To confirm the increase in the performance of this design compared to similar ones formed with a large number of nodal points, the final stage of the study is the analysis of structures in the ANSYS engineering analysis system.

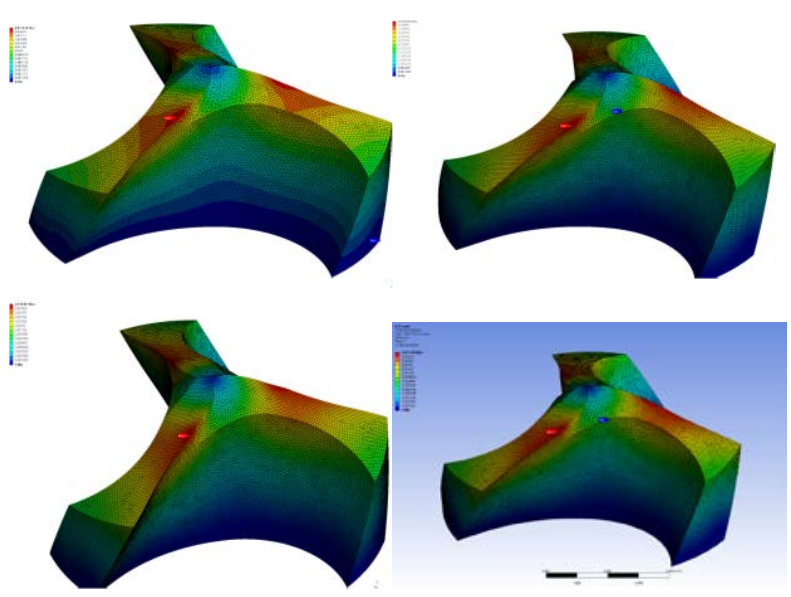

Fig. 3. The results of engineering analysis of structures with 8,7,6 and 5 control points

Table 1. The results of the internal stresses of each structure

\begin{tabular}{|c|c|}
\hline $\begin{array}{c}\text { Number of edge } \\
\text { reference points } \\
\text { on the thinning }\end{array}$ & $\begin{array}{c}\text { Maximum internal stress } \\
\text { values, Mpa }\end{array}$ \\
\hline 5 & 307 \\
\hline 6 & 346 \\
\hline 7 & 398 \\
\hline 8 & 422 \\
\hline
\end{tabular}

It follows from the table that the lowest values of internal stresses are shown by a design with 5 nodal points on the cutting edge of the studied area.

\section{Conclusion}

The design with the lowest value of internal stresses and a uniform distribution of the values of the angle of inclination of the cutting edge, allows you to increase productivity by more than $27 \%$ compared to analagic 
ones. Which allows us to draw the following conclusions:

1. A new three-fluted drills design method based on cutting theory and analytical geometry allows developing various designs with variable cutting edge geometry.

2. New functional connections allow getting rid of a sharp drop in the values of geometric parameters along the cutting edge, which increase the strength of the cutting part.

3. The developed model can be used as a theoretical basis for studying the tangent angle to the cutting edge. The new method makes it possible to develop designs of three-fluted drills with a straight cutting edge on the section of the chip groove of a rational shape, which increases the efficiency of the drill design during processing.

\section{Acknowledgments}

This research was funded by Ministry of Science and Higher Education of the Russian Federation, Grant No. 0707-2020-0031. This work was carried out using equipment provided by the Center of Collective Use of MSUT "STANKIN".

\section{References}

1. N. Baroiu, D. Boazu, C. Vasilache, T. Virgil, Appl. Mech. Mater, 371, 509-513 (2013)

2. H. Jung-Fa, D. Psang, Int. J. Mach. Tools Manuf. 42, 1181-1193 (2002)

3. N. Baroiu, V. Teodor, S. Berbinishi, N. Oancea, Proc. IN-TECH, (2011)

4. H. Jung-Fa, Int. J. Mach. Tools Manuf., 45(7-8), (2005)

5. L. Xiong, H. Shi, Y. Chen, ISAAT 9, 493-499 (2006)

6. P. Pivkin, A. Ershov, A. Nadykto, IEEE (FarEastCon, Vladivostok, Russia, 2020)

7. L. Xiong, H. Shi, Y. Chen, Chin. Mech. Eng., 18, 1165-1167 (2007)

8. N. Baroiu, N. Berbinschi, Fascicola suplimentara. 58(72), 31-34 (2013)

9. P. Pivkin, V. Grechishnikov, A. Ershov, A. Nadykto, Proc. SPIE 11540 (Advanced Manufacturing Technologies for Micro- and Nanosystems in Security and Defence III, 2020)

10. J. Hsieh, Int. J. Adv. Manuf. Technol., 45, 967-977 (2005)

11. S.N. Grigoriev, V.D. Gurin, M.A. Volosova, N.Y. Cherkasova, Materwiss. Werksttech, 44, 790796 (2013)

12. B. Nicusor, T. Virgil, B. Silviu, O. Nicolae, Adv. Mat. Res., 1036, 259-264 (2012).

13. H. Shi, [A Study on Curved Edge Drills. In: Metal Cutting Theory], Springer, Cham, (2018)
14. Y.E. Petukhov, N.V. Kolesov, S.Y. Yurasov, Russ. Eng. Res., 34, 374-380 (2014).

15. S.N. Grigoriev, V.I. Teleshevskii, Meas. Tech., 54, 744-749 (2011)

16. S.N. Grigoriev, M.P. Kozochkin, P.M. Pivkin, IEEE (FarEastCon, Vladivostok, Russia, 2020)

17. S.N. Grigoriev, O.V. Sobol, V M. Beresnev, et al., J. Frict. Wear, 35, 359-364 (2014).

18. S.P. Radzevich, Florida: CRC Press., 738 (2014).

19. T.-R. Lin, J. Mater. Process. Technol., 127(1), 493499 (2002)

20. F. Tang, J. Bai, X. H. Wang, Int. J. Adv. Manuf. Technol., 73(5-8), 659-667 (2014).

21. D. Livia, P. Dan, N. Brındas, M. Calin, R. Johannes, Int. J. Adv. Manuf. Technol., 83(9-12), 2111-2127 (2015)

22. S.N. Grigoriev, V.A. Grechishnikov, M.A. Volosova, X. Jiang, P.M. Pivkin, Mater. Sci. Eng. C, 971, 2 (2020)

23. B. Nicuşor, B. Silviu, T. Virgil, O. Nicoale, Tech. Mach. Build, 2012, 17-26 (2012)

24. C. Fetecau, N. Oancea, F. Stan, J. Mater. Process.Technol. 209(7), 3460-3468 (2009)

25. S.N. Grigoriev, V.A. Sinopalnikov, M.V. Tereshin, V.D. Gurin, Meas. Tech., 55, (2012)

26. S. Barnes, P. Bhudwannachai, A. Dahnel, Proc. ASME, 2B, (2013).

27. V.V. Kuzin, S.N. Grigoriev, M.A. Volosova, J. Frict. Wear, 36(1), 40, (2015)

28. A.V. Gusarov, S.N. Grigoriev, M.A. Volosova, Y.A. Melnik, A. Laskin, D.V. Kotoban, A.A. Okunkova, J. Mater. Process. Technol., 261, 213 (2018)

29. R.S. Khmyrov, S.N. Grigoriev, A.A. Okunkova, A.V. Gusarov, Phys. Procedia, 56, 345 (2014)

30. S.N. Grigoriev, G.M. Martinov, Procedia CIRP, 46, 525 (2016)

31. S.N. Grigoriev, D.A. Masterenko, V.I. Teleshevskii, P.N. Emelyanov, Meas. Tech, 55(11), 1311 (2013)

32. V.A. Grechishnikov, Y.E. Petukhov, P.M. Pivkin, Parts. Meas. Tech., 58, 848-853 (2015)

33. S.N. Grigoriev, M.A. Volosova, A.A. Okunkova, S.V. Fedorov, K. Hamdy, P.A. Podrabinnik, P.M. Pivkin, M.P. Kozochkin, A.N. Porvatov, J. Manuf. Mater. Process., 4, 96 (2020)

34. S.N. Grigoriev, M.A. Volosova, A.A. Okunkova, S.V. Fedorov, K. Hamdy, P.A. Podrabinnik, P.M. Pivkin, M.P. Kozochkin, A.N. Porvatov, Technologies., 8, 49 (2020)

35. S.N. Grigoriev, G.M. Martinov, Procedia CIRP, 1(1), 238 (2012)

36. M. Volosova, S. Grigoriev, A.Metel, A. Shein, Coatings, 8, 287, (2018)

37. A.S. Metel, V.P. Bolbukov, M.A. Volosova, S.N. Grigoriev, Yu.A. Melnik, Instrum. Exp. Tech., 57(3), 345, (2014) 
38. M.A. Volosova, S.N. Grigor'ev, V.V. Kuzin, Refract. Ind. Ceram., 55, 565, (2015)

39. M.A. Volosova, S.N. Grigor'ev, V.V. Kuzin, Refract. Ind. Ceram., 56, 197, (2015)

40. M.A. Volosova, S.N. Grigor'ev, V.V. Kuzin, Refract. Ind. Ceram., 55, 487, (2015)

41. V.V. Kuzin, S.N. Grigoriev, M.A. Volosova, J. Frict. Wear, 35(6), 505, (2014)

42. V.V. Kuzin, S.N. Grigor'ev, M.A. Volosova, Refract. Ind. Ceram., 54, 376, (2014)

43. S. Berbinschi, N. Baroiu, T. Virgil, N. Oancea, New technologies in manufacturing, (2011)

44. S.N. Grigoriev, M.A. Volosova, A.A. Okunkova, S.V. Fedorov, K. Hamdy, P.A. Podrabinnik, ... , A.N. Porvatov, J. Manuf. Mater. Process., 4(3), 96 (2020) https://doi.org/10.3390/jmmp4030096

45. P.M. Pivkin, A.B. Nadykto, V.A. Grechishnikov, M.A. Volosova, I.V. Minin, S.N. Grigoriev, Emerging Imaging and Sensing Technologies for Security and Defence V; and Advanced Manufacturing Technologies for Micro-and Nanosystems in Security and Defence III, 11540, 115401G (2020) https://doi.org/10.1117/12.2574391

46. S.N. Grigoriev, V.A. Grechishnikov, M.A. Volosova, X. Jiang, P.M. Pivkin, IOP Conference Series: Materials Science and Engineering, 971(2), $022065 \quad$ (2020) doi: 10.1088/1757-899X/971/2/022065

47. P.M. Pivkin, V.A. Grechishnikov, A.A. Ershov, A.B. Nadykto, Emerging Imaging and Sensing Technologies for Security and Defence V; and Advanced Manufacturing Technologies for Microand Nanosystems in Security and Defence III, 11540, $1154014 \quad$ (2020) https://doi.org/10.1117/12.2574392 